\title{
Practice and Research on the Novel Interactive Teaching and Learning Methodology for Clothing Design Major Education
}

\author{
Jiarong $\operatorname{Han}^{1}$ \\ ${ }^{1}$ Northeast Dianli University ,Jilin , Jilin 132012 China
}

\begin{abstract}
In this paper, we research on the novel interactive teaching and learning methodology for clothing design major education. Clothing in the cultivation of innovative talents should be on the premise of enhancing knowledge base and at the same time pay attention to the cross of disciplines and combination, make subject mutual infiltration and influence each other. Teachers should combine the product experience and innovative thinking method and design performance to help the students complete the whole process of fashion design. In the future research, we will combine the advances of multimedia teaching with our clothing design major education to make it more effective.
\end{abstract}

Keywords: Interactive Teaching and Learning; Clothing Design; Education Reform.

\section{Introduction}

Higher apparel education in our country after nearly 30 years of development which has formed a large scale and has prepared art design for the apparel industry, engineering, management, marketing. A large number of talents have emerged. But there is still a hierarchy concentration, different levels of knowledge, problem solving ability is not strong, the lagged development and other issues. Colleges and universities to cultivate students can adapt to society, whether has the practical ability which is the important measure of talent, in fact has become the important measure of college teaching quality. Although many clothing colleges try in educational levels, training goal, teaching, curriculum teaching reform, but in both the depth and breadth and impact, far from of clothing in innovative talents training target, cannot effectively enhance and improve the students' intelligent thinking and problem solving skills [1]. For with the diversity of art design with engineering education clothing, its professional education idea is an open, expansibility, with design and creative. As the practice skilled professional garment specialty, should develop the consultation, the reverse the past theoretical basis, first to the practice of senior to start practice, formed the cultivation of practice and theory in parallel. Because students in class didn't understand the basic operation mode of manufacturing enterprises, so they cannot understand the course content.

Employment education, vocational education is to cultivate students into the enterprise should be able to use them, after this request must strengthen the practice teaching. Clothing in the decrease of the quality of the students in recent years, at the same time, the traditional heavy theory of light practice subject standard education and clothing enterprise production line practical existence serious phenomenon, the use of students' professional ability and migration ability are relatively weak, mount guard adjustment period is longer, so the teaching mode and teaching content reform, classroom teaching practice to cause enough attention and understanding. Scientific and reasonable curriculum system plays an important role in the students' knowledge structure formation. Clothing in the cultivation of innovative talents should be on the premise of enhancing 
knowledge base and at the same time pay attention to the cross of disciplines and combination, make subject mutual infiltration and influence each other [2]. Face up to the problems in personnel training, with advanced ideas and talent training quality education as the instruction, from teaching concept, talents cultivation target, cultivation process and ways in hands, seize the outstanding students' innovative spirit and practice ability training, the key scientific and systematic design talent training plan and content, actively explore talents cultivation mode and the way of personality of students' autonomous learning and development [3-5]. Classified teaching is determined by the students' individual differences and professional structure, it from the students' knowledge level, in all aspects of the student's ability, specialty, hierarchical classification, determine different levels of training target, eventually make students average development. With the continuous development of science and technology, electronic teaching, multimedia teaching has played a more and more important role in practice. In clothing production process, training sessions, we use modern teaching facilities for teaching. It is simple, intuitive, and economical teaching means in teaching. Since clothing specialized teaching is different from the literacy class teaching, there should be unique. Focuses on cultivating the student beginning ability, carry out various kinds of professional skills competition, cultivate the students' sense of competition in the competition, cultivate the students' interest in the competition which will make the students master the skill. In the figure one, we show the method.

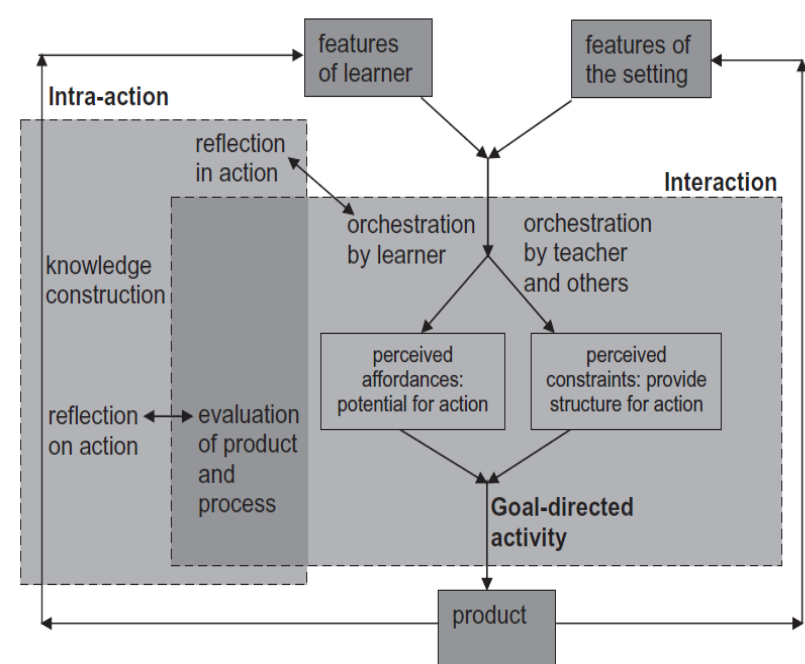

Figure 1.The Flowchart of the Interactive Teaching and Learning Methodology

In this paper, we research on the novel interactive teaching and learning methodology for clothing design major education. Innovative talents is the basis of man's all-round development, innovative talents cultivation in imparting his knowledge at the same time, more attention should be paid to the student individuality development, attach importance to cultivating students' practical exploration of scientific spirit and critical spirit. Clothing professional innovative talents training goal is to cultivate students with a solid professional knowledge and strong innovation consciousness and the outstanding practice ability. In the next sections, we will show the issues in detail.

\section{Our Proposed Interactive Methodology}

The Introduction of Clothing Design Major Education. Society has gone into the era of knowledge economy. Against the above background, we must explore how to do a good job in industry. As the society needs to develop different levels of different specifications of the technical personnel and for the local economic construction service, we need high-quality education opportunities. Cultivate the students' professional ability which is not a task or a course teaching links, must stand in the professional ability is the height of the school for vocational 
colleges, the comprehensive optimization of the teaching plan. Before teaching plan, the school must carry on the investigation and study, according to the market demand, analysis of professional post personnel training target of vocational ability structure, determine the applicable talents must possess a variety of special ability. On this basis, according to the specific ability, ability to implement integrated target required basic knowledge, professional knowledge and professional skills, and ability to elements and disassembling is analyzed, the corresponding professional teaching plan. In specialized course teaching in the past, is basically all the end of the course, to focus to corporate practice, the effect of the hands of any of such practice assault, so should take learning, while practice, namely the theory teaching and practice teaching, skills training synchronously.

Class teachers arrangement design renderings homework, plate class, students need to be able to according to drawings to produce various clothing, the example of faultiness in the design process for further modification and in the technology of class students to this series of clothing to write out the process flow diagram, and one representative clothing can be made into clothing, then make the problems timely feedback to the teacher, in order to make further changes. This requires that each teacher should understand students' learning process, overlapping process between master courses so that students understand both the whole process of the design and production and cultivate the innovative ability in practice which will be meaningful.

The Interactive Teaching and Learning Methodology. Experience and interactive type teaching from experiential learning, refers to the teaching process according to students' cognitive characteristics and laws, by creating real, real situation simulation, rendering or reproduce the teaching content, so that the students in the process of experience get more visual perceptual knowledge, understanding and gradually building knowledge, developing ability of teaching form. Clothing design is groups demand, product attributes and the mutual coordination between and among social value. In product design, product user experience designers to pursue. Rich in originality, certain life experience, accurate product experience is often ignored in the costume design teaching. Teachers can combine the product experience, innovative thinking method and design performance to help students complete the whole process of fashion design. In the teaching guide students to observe the use of all kinds of clothing function and detail design, obtain clear experience and intuitive feelings. The advantages of the interactive education could be summarized into the following parts. (1) Because of the interactive teaching requires students to communicate with others in study art design course, interact with the teacher and so on demand students to preview before class work virtually supervise the students autonomous learning after class, to avoid students lazy, raise the efficiency of classroom teaching. (2) Interactive teaching makes students and teachers in the classroom to form good relations of cooperation, fully arouse the enthusiasm of the students as well as active classroom atmosphere, more help teachers find the fun of class, relationship between teachers and students have been improved. (3) Class is not conducive to change students ever teaching disadvantages of positive thinking, promote their integrated into the classroom atmosphere, helps the student to the establishment of personalized thinking, not only let students learn knowledge, more learned how to communicate with others about the inspiration of art and design and experience. (4) Also increase accordingly to the requirement of the teacher, teachers need to actively in the class prepares a lesson earnestly, the likely scenario plan, think about what kind of problem solving is helpful to the formation of good interaction, how to make students fully integrated into the class. 
Interactive teaching is a new, in-depth and comprehensive teaching activities, art design is a very subjective process, once the two combinations which need the teacher is a very powerful classroom control and patience for students. Interactive teaching and traditional teaching methods is a fundamental difference, school education idea, the teacher's teaching methods and students' learning attitude and update all need to do a thorough reform. Several methods of interactive teaching in the colleges and universities could be summarized into the following parts. (1) The problem of induction. Problem of induction requires students to a detailed preview before class, combined with their own thinking, summarizes their confused problems and self-knowledge that difficulties, through the interactive discussion in class and all the students to discuss, and then brainstorm of knowledge by the teacher again later, sum up out the real answer. This process can meet the demands of modern teaching, and students need to consciously to generate interest in knowledge and curiosity about knowledge and help them form the ability of independent learning and thinking, this is the students must possess the ability after entering society in the future. (2) Situation and environment simulation method. Scene creation is a cannot be ignored in the contemporary teaching effective method, the teacher as the organization man in the classroom instruction to create a virtual life scenes, the students in such a scenario for targeted art design activities. (3) Topics discussed method. Only grasp the theme, in accordance with the established route to explore, think, is likely to achieve the teaching objective in the teacher's, if not for the theme, in the process of interactive teaching because the students' thinking active, is likely to lead to slant direction in the discussion process and the influence of teaching progress. (4) Multimedia teaching method. Using modern multimedia technology can be square serious classroom teaching atmosphere is lively students feel high and new technology and a variety of relationship between art and design which will be effective. Interactive teaching compared with traditional teaching, the biggest difference is that the traditional case teaching model, the teacher is always on high, students have to follow the teacher's advice and there cannot be any violation, this is a one-way, no vitality of teaching mode which should be modified.

The Novel Interactive Pattern for Clothing Design Major Education. Clothing is practical, and its functional properties is to service for the consumer, its protection function, such as recognition to rational thinking and analysis. Aesthetic of clothing should also be at the same time, its decoration attribute for consumers to accept. Clothing creation in his works as the carrier, in the consumption for the purpose of activities which is not a simple painting performance, at the same time it should not be a simple industrial manufacturing. The curriculum is the embodiment of the talent training scheme, and the personnel training specification and target carrier directly. The curriculum ideas directly affect to achieve the goals of talents cultivation and a good curriculum system and talent cultivation model is the realization of the core of talents cultivation.

Teaching staff is the core of the realization of teaching reform and innovation and the motive power. Teacher theory to study the depth and breadth, practical skills and practical experience of abundance skilled, the theoretical frontier of innovation capability and market demands of master degree, directly determines the level and quality of teaching. Project teaching mode requires teachers must clear their own role, to realize the students' knowledge infusion of passive accept not by teachers, but under the guidance of teachers, the students take the initiative to construct. Teachers on the teaching methods of it, the main purpose of the design problem is by students in problem solving activities, learning knowledge and skills, stimulate students' learning motivation, develop students' thinking ability, imagination and the 
ability of self-reflection; At the same time, encourage students to learn knowledge skills applied to the daily study and life and even directly or indirectly involved in the activities in the social production which will be of great importance.

\section{Conclusion}

In this paper, we research on the novel interactive teaching and learning methodology for clothing design major education. Clothing design is a cover a wide utility of course, it is the theory and practice are strong discipline and a lot of theory needs to be in a lot of practice to understand and grasp, through learning of this course to improve students' aesthetic ability and painting skills, design ability and innovation ability to improve the comprehensive quality of students and of course, in order to adapt to the demand of the society, therefore, the teaching of project design is the key. Teachers should put the theory and practice of teaching in class teaching organically, and fully tap the students' creative potential to improve students' comprehensive ability to solve practical problems. Our method will interactively enhance the teachers and students at the same time which is meaningful.

\section{References}

[1] Guan J. A Brief Discussion on the Teaching Reform of Clothing Design Major in Higher Vocational Colleges[J]. Science Education Article Collects, 2014.

[2] Huang G. Study on the On-campus Productive Practice Base Model for the Clothing Design Major of Higher Vocational Colleges[J]. Art \& Design, 2014.

[3] Luo Y. On the Effective Design of Assessment Methods for General Courses: A Case Study on Animation and Clothing Culture Course $[\mathrm{J}]$. Science Education Article Collects, 2014.

[4] Zhang X F, Huang R Q. Virtual display design and evaluation of clothing: a design process support system[J]. International Journal of Technology \& Design Education, 2014, 24(2):223-240.

[5] Ping X B. General Education Modular Curriculum Design of Higher Vocational Business Major[J]. Journal of Liaoning Higher Vocational, 2014. 